\title{
Effects of Ausforming Procedure and Following Annealing Treatment on Microstructural Characteristics in Cobalt
}

\author{
Jian Tu ${ }^{1,2} \cdot$ Kun-Feng Zhou ${ }^{1} \cdot$ Zhi-Ming Zhou $^{1,2} \cdot$ Can Huang $^{1} \cdot{\text { Zhi-Gang } \text { Chen }^{3}}^{3}$
}

Received: 10 April 2017/Revised: 14 May 2017/Published online: 21 June 2017

(C) The Chinese Society for Metals and Springer-Verlag GmbH Germany 2017

\begin{abstract}
The effects of ausforming procedure and subsequent annealing treatments on microstructures of cobalt (Co) samples are investigated by electron channeling contrast and electron backscatter diffraction techniques. Results show that the ausformed Co samples consist of coarsen blocky laths (single $\varepsilon$ phase) with the irregular morphology and the ultra-fine acicular laths (dual phase: $\gamma$ and $\varepsilon$ ) with the slender and rectangular morphologies. As compared to the slight reduction sample, the much denser acicular laths are observed in the heavily ausformed sample. In addition, recrystallization behavior and annealing-induced $\gamma \rightarrow \varepsilon$ transformation have occurred in ausformed Co samples during the annealing treatment.
\end{abstract}

KEY WORDS: Ausforming; Ultra-fine grain; Electron backscatter diffraction (EBSD); Electron channeling contrast (ECC); Cobalt

\section{Introduction}

Compared to coarse-grained metallic materials, ultra-fine grains exhibit unusual mechanical properties such as remarkable work hardening and ductility [1-5]. The ultrafine grains can be fabricated from metals subjected to the ultra-high strain by severe plastic deformation (SPD)

Available online at http://link.springer.com/journal/40195

Zhi-Ming Zhou

zhouzhiming@cqut.edu.cn

Zhi-Gang Chen

zhigang.chen@usq.edu.au

1 School of Materials Science and Engineering, Chongqing University of Technology, Chongqing 400054, China

2 Chongqing Municipal Key Laboratory of Institutions of Higher Education for Mould Technology, Chongqing University of Technology, Chongqing 400054, China

3 Centre for Future Materials, University of Southern Queensland, Springfield, QLD 4360, Australia technology [6-9], including accumulative roll bonding [10-12], equal-channel angular pressing [13-15], friction stir welding [16-18], and high-pressure torsion [19, 20]. The recent significant progress has been summarized in the review articles [1, 6, 9]. It should be noted that the complex procedure and the low efficiency of SPD technologies have limited their practical application in fabricating ultra-fine grains [21].

The optimized ausforming technology, integrating hotrolling deformation followed by controlled cooling, is applied to achieve ultra-fine grains for steels [22-24]. Ultra-grain refinement of steel can be realized via controlling dynamic phase transformation from $\gamma$ (face-centered cubic) phase to $\alpha$ (body-centered cubic) phase in ausforming treatment [22-24]. Such a success in steel raises one interesting topic: whether ausforming treatment can be used to some metallic materials with $\gamma \rightarrow \varepsilon$ (hexagonal closed-packed) transformation.

Metallic cobalt (Co) has two crystallographic structures, i.e., $\varepsilon$ and $\gamma$ phase [25]. The ideal phase transition temperature between the $\varepsilon$ and $\gamma$ is about $673 \mathrm{~K}$. However, the energy difference between $\varepsilon$ and $\gamma$ phases is so small that 
random inter-growth of such two phases is common [26]. In addition, $\gamma$ phase is meta-stable and a strain-induced $\gamma \rightarrow \varepsilon$ transformation can happen during deformation process, leading to work hardening and higher ductility [27-29]. On the other hand, Co with HCP structure has very low stacking fault energy (SFE) [25], so the profuse deformation modes can be operated in Co during the plastic deformation, resulting in work hardening. Interestingly, the above metallurgical behavior will be involved in Co during the ausforming processes. Thus, the understanding of the origin and underlying mechanism of grain refinement induced by ausformed treatment in Co is highly needed.

In this work, the effects of initial ausforming procedure and subsequent annealing treatments on microstructural evolution of Co samples are systematically investigated by using electron channeling contrast (ECC) and electron backscatter diffraction (EBSD) techniques, aiming at preliminarily probe possible potentials of the optimal ausforming routes for Co.

\section{Experimental}

The received material used in this investigation was highpurity Co (99.9\%). The received Co samples were the fully recrystallized microstructure with a strong basal texture $[30,31]$. The ausforming was processed by one single-pass rolling under $600{ }^{\circ} \mathrm{C}$ (above phase transformation temperature $405{ }^{\circ} \mathrm{C}$ ) to reduce the thickness of the sample from 2 to $1.84 \mathrm{~mm}$ (8\% reduction) and 2 to $1 \mathrm{~mm}(40 \%$ reduction) within $8 \mathrm{~s}$ and then rapid water quenching. The rollers were heated to $400{ }^{\circ} \mathrm{C}$ and the rapid rolling speed was set as $0.5 \mathrm{~m} / \mathrm{s}$ (linear velocity), making the temperature difference be reduced as much as possible. Subsequently, the $40 \%$ ausformed Co underwent the annealing treatments at $200{ }^{\circ} \mathrm{C}$ for $1 \mathrm{~h}, 360{ }^{\circ} \mathrm{C}$ for $10 \mathrm{~min}$ and $360{ }^{\circ} \mathrm{C}$ for $1 \mathrm{~h}$, respectively, followed by water cooling.

Microstructures of the rolling direction and transverse direction (RD-ND) plane of the treated specimens were characterized by field emission gun scanning electron microscopy (FEG-SEM) measurements. The specimens were mechanically ground by using $\mathrm{SiC}$ paper (4000\# at the final step), and then electro-polishing was conducted at $20 \mathrm{~V} / 0.5 \mathrm{~A}$ at $-20{ }^{\circ} \mathrm{C}$ for $50 \mathrm{~s}$ in a solution, consisting of $10 \mathrm{ml}$ glycerinum, $20 \mathrm{ml}$ perchloric acid, and $70 \mathrm{ml}$ alcohol, and thus a good surface quality can be obtained for SEM examinations. The specimens were characterized by ECC technique in a Zeiss Sigma HD FEG-SEM. In addition, the step sizes used for EBSD were varied from 0.07 to $2 \mu \mathrm{m}$, depending on the grain sizes in different treated samples.

\section{Results and Discussion}

Figure 1 shows the typical microstructural characteristic of $8 \%$ ausformed Co obtained by ECC under different magnifications. As can be seen from Fig. 1a, $8 \%$ ausformed Co has an inhomogeneous microstructure in which the acicular laths and blocky laths coexist. The corresponding higher magnification images (Fig. 1b, c) show that the blocky laths have the irregular shape. The high-magnification images of the acicular laths (Fig. 1d-f) show that the acicular laths have slender and rectangular morphologies. From Fig. 1e and f, the length and width of these slender laths can be estimated to be several micrometers and one hundred of nanometers, respectively, while the rectangular laths have nanoscale size in length and width.

Figure 2 shows the microstructural characteristics for $40 \%$ ausformed Co. Compared to $8 \%$ ausformed Co, $40 \%$ ausformed Co has much denser laths inside one prior austenite grain, as shown in Fig. 2b. An enlarged image of the white rectangle in Fig. $2 b$ (Fig. 2c) reveals that the slender laths have two flow directions (marked by blue arrows). Furthermore, the laths in the different prior austenite grain boundaries (marked by red lines) have different flow directions, as indicated in Fig. 2d. The highmagnification images (Fig. 2e, f) show that there exist nano-sized rectangular and slender substructures in the acicular laths.

Figure 3 shows the EBSD maps for the $8 \%$ (a) and $40 \%$ (b) ausformed Co. The inverse pole figures (IPFs) of the $8 \%\left(a_{1}\right)$ and $40 \%\left(b_{1}\right)$ ausformed Co show that the ausformed treatment can weaken the initial (0001)basal texture of Co. Figure $3 a_{2}$ and $b_{2}$ shows a dual-phase microstructure, including $\gamma$ phase (blue color) and $\varepsilon$ phase (red color). Thus, the dual-phase microstructure is kept in the room temperature. For $8 \%$ ausformed Co, the amounts of $\gamma$ phase and $\varepsilon$ phase can be calculated for $55.3 \%$ and $44.7 \%$, while for $40 \%$ ausformed Co, $\varepsilon$ phase $(65.9 \%)$ occupy more obvious superiority than $\gamma$ phase $(34.1 \%)$. Thus, much more residual austenite $\gamma$ phases are kept in $8 \%$ ausformed Co. The grain boundary maps (Fig. $3 a_{3}, b_{3}$ ) show that there exist different grain boundaries including low angle grain boundaries (LABs, marked by gray lines), high angle grain boundaries (HAB, marked by black lines), annealing twinning boundaries ( $\sum 3$ boundaries, marked by blue lines) in $\gamma$ phase and special boundaries with $70.5^{\circ} /<11 \overline{2} 0>$ misorientation (SB, marked by red lines) in $\varepsilon$ phase. Actually, it cannot be found effectively by EBSD because most of the misorientations are $<2^{\circ}$. Thus, many blank areas are revealed in Fig. $3 b_{3}$, showing that the boundaries of these laths are almost parallel to each other. $\sum 3$ boundaries are easily observed in $\gamma$ phases, because Co with very low stacking fault is highly susceptible to 


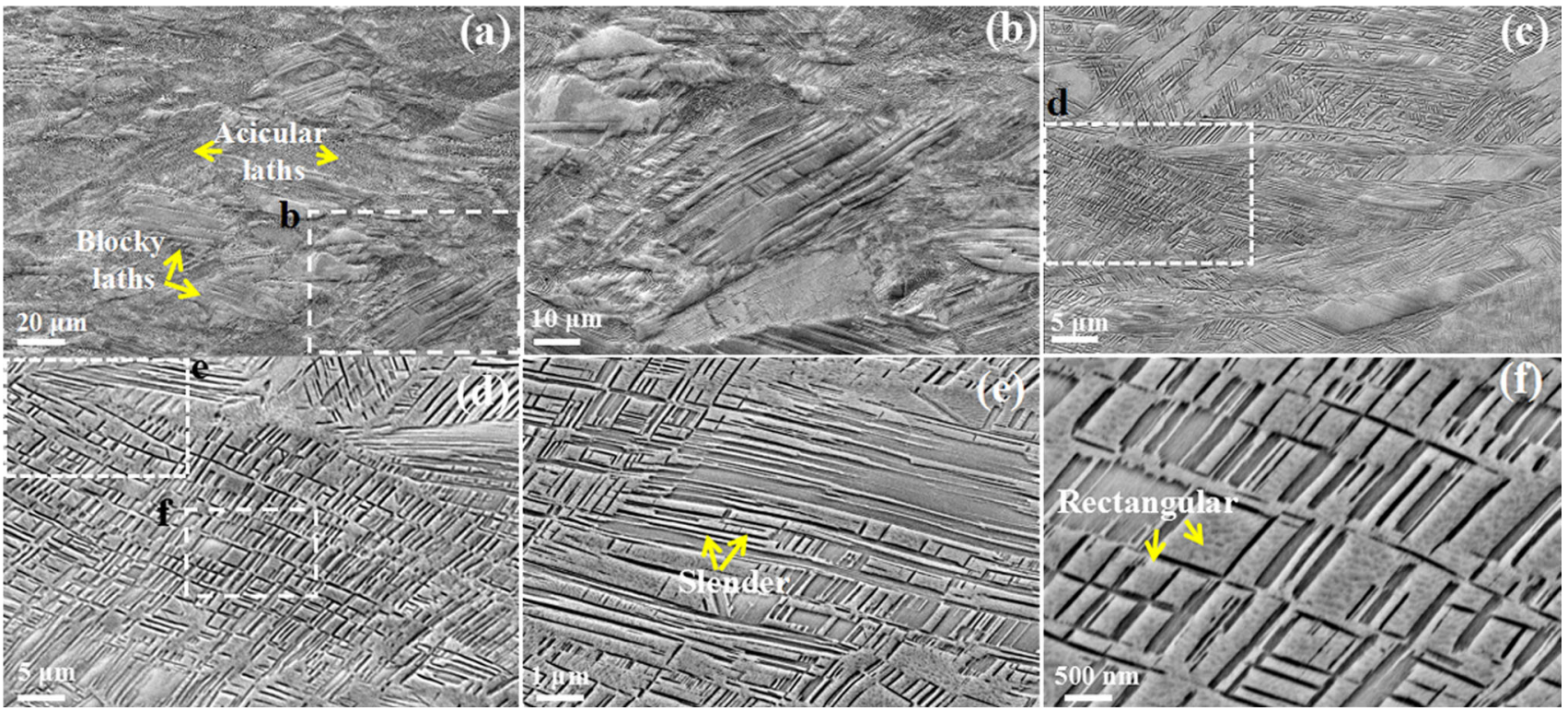

Fig. 1 Morphological characteristics of ausformed Co sample with $8 \%$ reduction by ECC technology under different magnifications: a the coexistence of acicular laths and blocky laths; $\mathbf{b}$ and $\mathbf{c}$ irregular morphologies in blocky laths; $\mathbf{d}$ slender and rectangular morphologies in the acicular laths; e slender laths, $\mathbf{f}$ rectangular laths within the white rectangles in $\mathbf{d}$
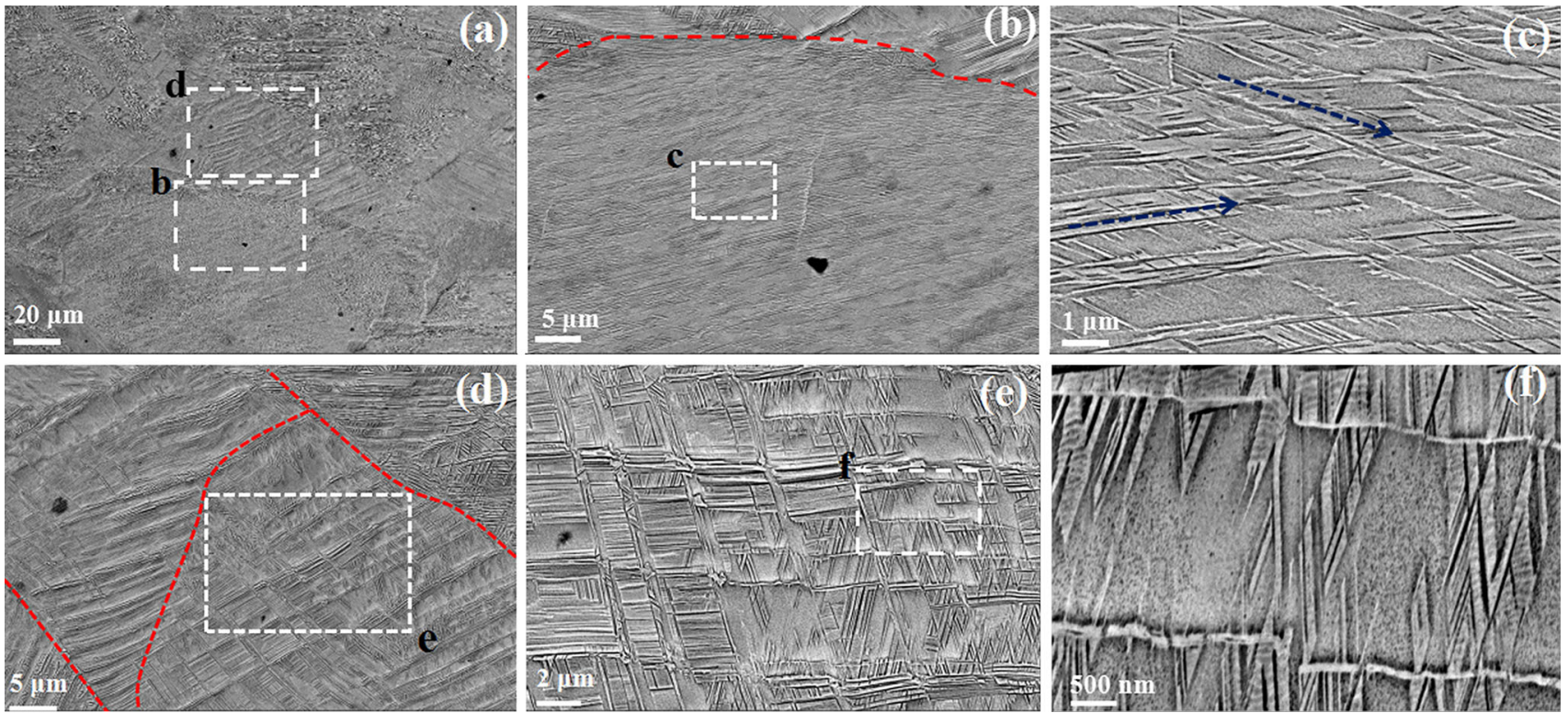

Fig. 2 Morphological characteristics of ausformed Co sample with $40 \%$ reduction by ECC technology under different magnifications: a acicular laths in each grain in different flow directions; b high density of laths inside one prior austenite grain; $\mathbf{c}$ two flow directions (marked by blue arrows) for the slender laths; $\mathbf{d}$ different flow directions inside the different prior austenite grain; $\mathbf{e}, \mathbf{f}$ nano-sized rectangular substructures in acicular laths

annealing twins during the annealing treatment [25]. In addition, SBs with $70.5^{\circ} /<11 \overline{2} 0>$ misorientation are formed after $\gamma \rightarrow \varepsilon$ transformation, which is strictly abide by Shoji-Nishiyama (S-N) orientation $\left(\{111\}_{\gamma} / /\{0001\}_{\varepsilon}\right.$ and $<110>_{\gamma} / /<11 \overline{2} 0>_{\varepsilon}$ ) $[26,30]$.

Figure 4 shows the grain boundary misorientation statistical results of $\gamma$ phase and $\varepsilon$ phase for $8 \%$ and $40 \%$ ausformed Co, in which $2^{\circ}-14^{\circ}$ misorientation in $\varepsilon$ and $\gamma$ phases, $60^{\circ}$ misorientation in $\gamma$ phase, and $70.5^{\circ}$ misorientation in $\varepsilon$ phase are observed. From which, there is no preference to rotation axis for $2^{\circ}-14^{\circ}$ misorientation; however, the $<111>$ rotation axis for $60^{\circ}$ misorientation in $\gamma$ phase and $<11 \overline{2} 0>$ rotation axis for $70.5^{\circ}$ misorientation in $\varepsilon$ phase can be seen. Moreover, the higher density of LABs $\left(2^{\circ}-14^{\circ}\right.$ misorientation) exists in $40 \%$ ausformed Co, indicating that more dislocations are involved in the heavy 


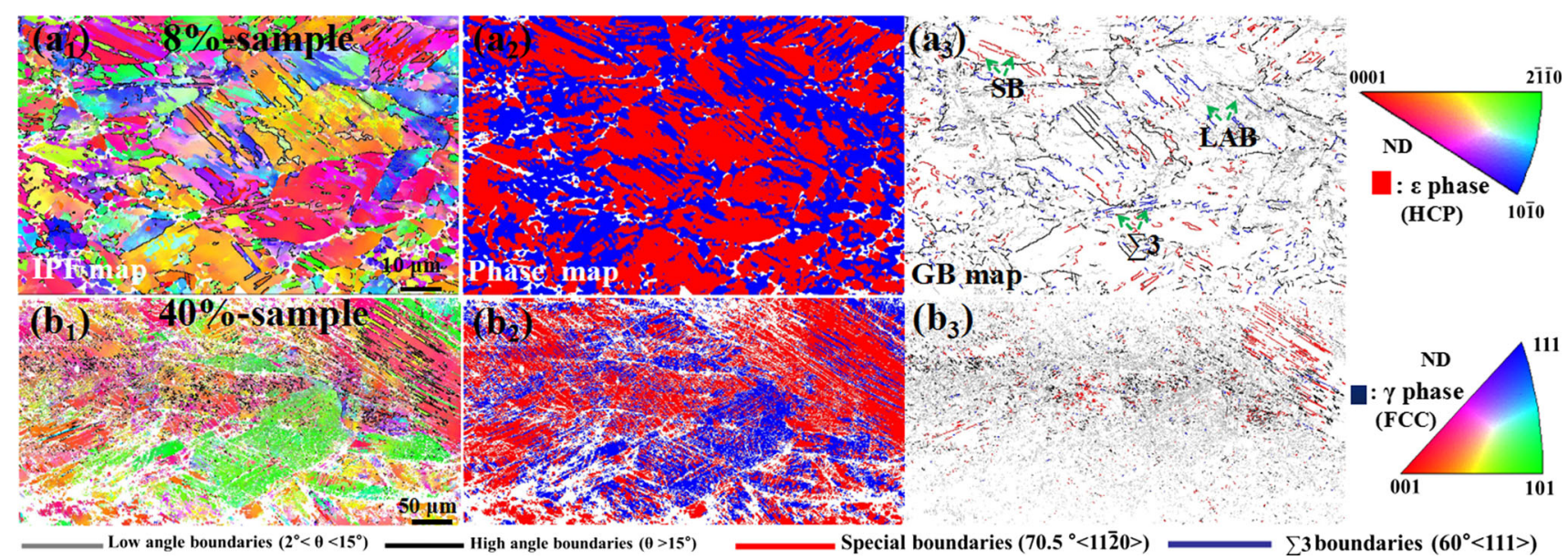

Fig. 3 EBSD maps for the ausformed Co samples. IPF maps for the $8 \%$ reduction sample $\mathbf{a}_{\mathbf{1}}$ and the $40 \%$ reduction sample $\mathbf{b}_{\mathbf{1}}$; phase maps in $\mathbf{a}_{2}$, $\mathbf{b}_{\mathbf{2}}$ showing a dual-phase microstructure, including $\gamma$ phase (blue color) and $\varepsilon$ phase (red color); grain boundary (GB) maps in $\mathbf{a}_{3}, \mathbf{b}_{\mathbf{3}}$ showing the GBs characteristics, including low grain boundaries (LABs, marked by gray lines), high grain boundaries (HAB, marked by black lines), annealing twinning boundaries ( $\sum 3$ boundaries, marked by blue lines) in $\gamma$ phase and special boundaries with $70.5^{\circ} /<11 \overline{2} 0>$ misorientation ( $\mathrm{SB}$, marked by red lines) in $\varepsilon$ phase
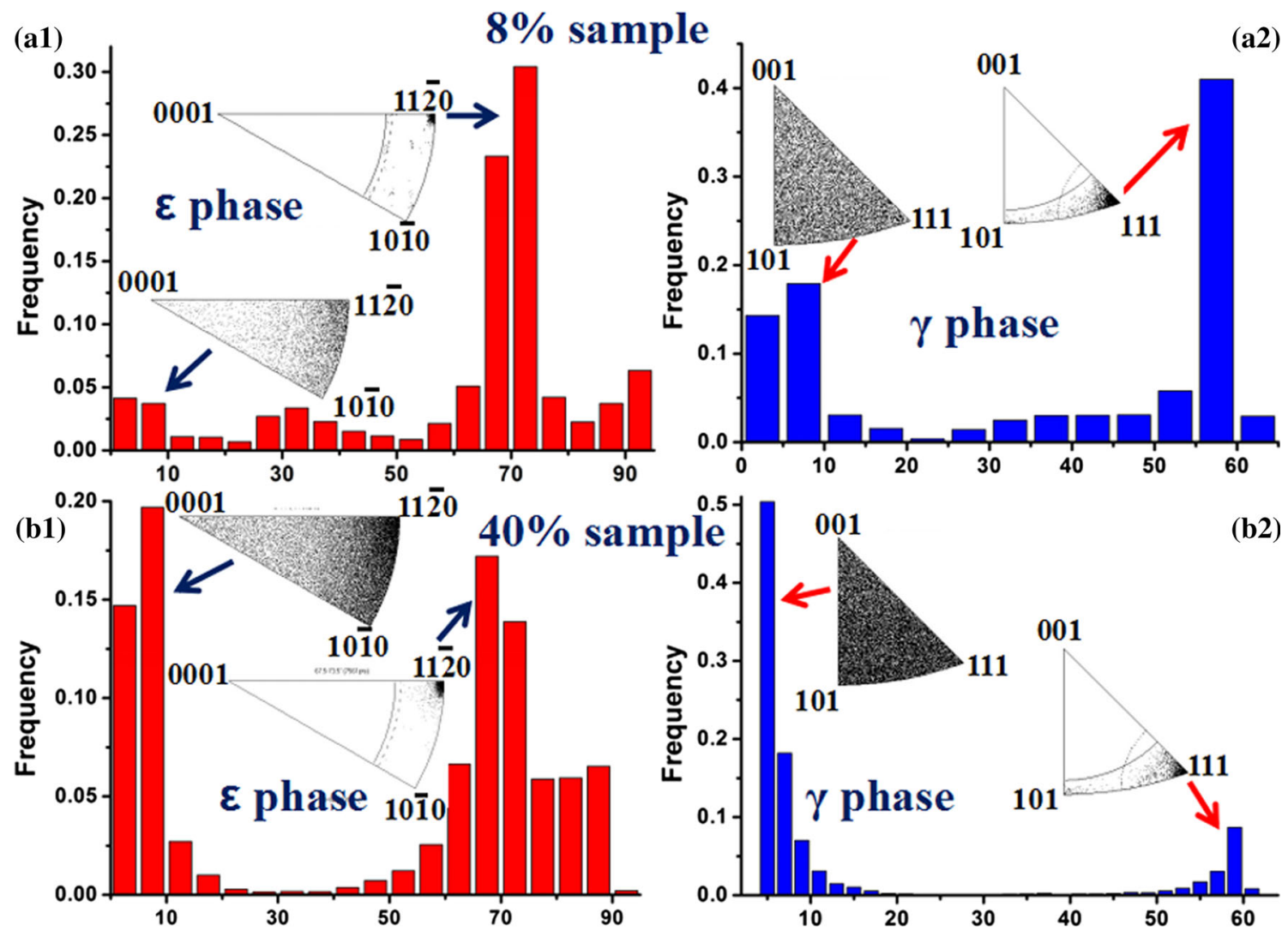

Fig. 4 GB misorientation angle statistics of $\gamma$ phase and $\varepsilon$ phase, in which the misorientation distributions in $\varepsilon$ and $\gamma$ phases for $8 \%$ and $40 \%$ reduction samples are shown in $\mathbf{a}, \mathbf{b}$

strain sample. It is assumed that LAB is caused by the movement and interaction of high density of dislocations, which are ascribed to the multiplication and evolution of dislocations during the ausforming process. Moreover, $\sum 3$ boundaries $(60 \%<111>)$ in $\gamma$ phase and SB $\left(70.5^{\circ} /<11 \overline{2} 0>\right)$ in $\varepsilon$ phase mix in varying proportions, indicating that both of them are inevitably in the slight and heavy strain samples. 
The full Euler angles images (Fig. $5 \mathrm{a}_{1}-\mathrm{d}_{1}$ ) show that the acicular and blocky laths coexist in ausformed Co $(8 \%$ and $40 \%$ reduction). Figure $5 \mathrm{a}_{2}$ reveals the unregular blocky laths, and these blocky laths can be indexed as $\varepsilon$ phase (red color), while the acicular laths are $\varepsilon$ phase and $\gamma$ phase, showing that the high-temperature $\gamma$ phase has not completely transformed into $\varepsilon$ phase during the cooling process. Figure $5 \mathrm{a}_{3}$ shows that acicular laths have abundant LABs, indicating that the acicular laths are almost parallel to each other. Figure $5 b_{1}-d_{1}$ shows the substructures of acicular laths, revealing that the acicular laths consist of the slender and rectangle substructures. Figure $5 b_{2}-d_{2}$ shows that these slender and rectangle substructures can be corresponding to $\varepsilon$ phase or $\gamma$ phase. Figure $5 b_{3}-d_{3}$ shows that the boundaries of slender laths consist of SBs $\left(70.5^{\circ} /<11 \overline{2} 0>\right)$ and LABs.
In order to understand the effect of the subsequent annealing treatments on microstructural evolution of the $40 \%$ ausformed $\mathrm{Co}$, the microstructural characteristics after annealing treatment by ECC are investigated and the results are shown in Fig. 6. Figure 6a shows the typical image of annealed ausformed Co (40\% reduction) at $200{ }^{\circ} \mathrm{C}$ for $1 \mathrm{~h}$. As increasing the annealing temperature $\left(360{ }^{\circ} \mathrm{C}\right)$ under a short time $(10 \mathrm{~min})$, there exists a partly recrystallization grains (Fig. 6b). As the prolonging holding time $(1 \mathrm{~h})$ at $360{ }^{\circ} \mathrm{C}$, the degree of recrystallization is obviously increased for the sample treated at $360{ }^{\circ} \mathrm{C}$ for $1 \mathrm{~h}$ (Fig. 6c). As can be seen from Fig. 6 , the recrystallization behavior becomes obvious as the prolonging holding time and the increasing annealing temperature for ausformed Co, confirming the weak thermal stability in ausformed Co under the elevated temperature above $360^{\circ} \mathrm{C}$.
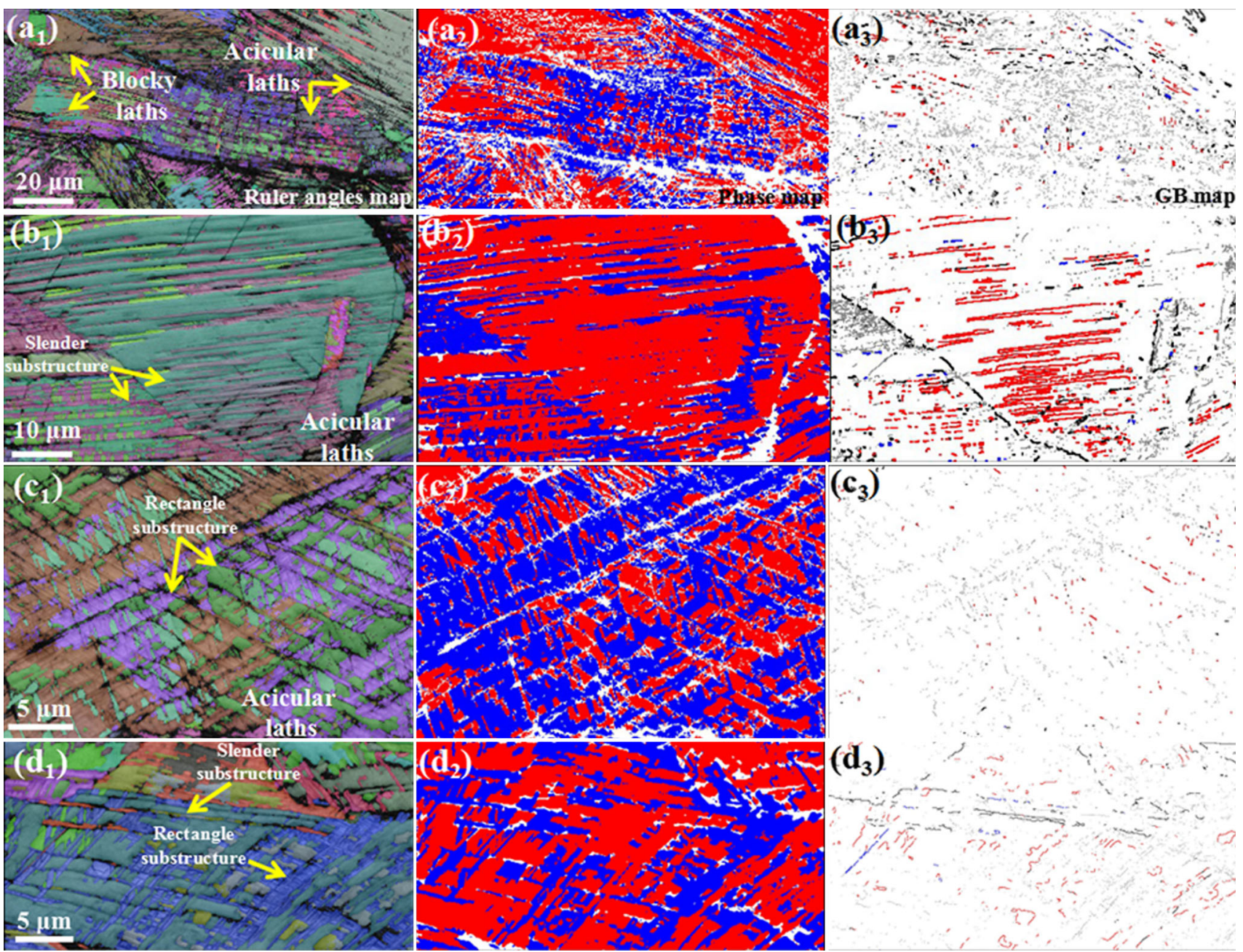

Fig. 5 Magnified high-resolution EBSD maps for ausformed Co with $40 \%$ reduction sample showing blocky and slender laths in $\mathbf{a}_{\mathbf{1}}, \mathbf{b}_{\mathbf{1}}, \mathbf{c}_{\mathbf{1}}, \mathbf{d}_{\mathbf{1}}$. Phase maps in $\mathbf{a}_{2}, \mathbf{b}_{\mathbf{2}}, \mathbf{c}_{\mathbf{2}}, \mathbf{d}_{\mathbf{2}}$ showing a dual-phase microstructure, including $\gamma$ phase (blue color) and $\varepsilon$ phase (red color). Grain boundary maps in $\mathbf{a}_{\mathbf{3}}, \mathbf{b}_{\mathbf{3}}, \mathbf{c}_{\mathbf{3}}, \mathbf{d}_{\mathbf{3}}$ showing low grain boundaries (LABs, marked by gray lines), high grain boundaries (HAB, marked by black lines), annealing twinning boundaries (marked by blue lines) in $\gamma$ phase and special boundaries with $70.5^{\circ} /<11 \overline{2} 0>$ misorientation (SB, marked by red lines) in $\varepsilon$ phase 

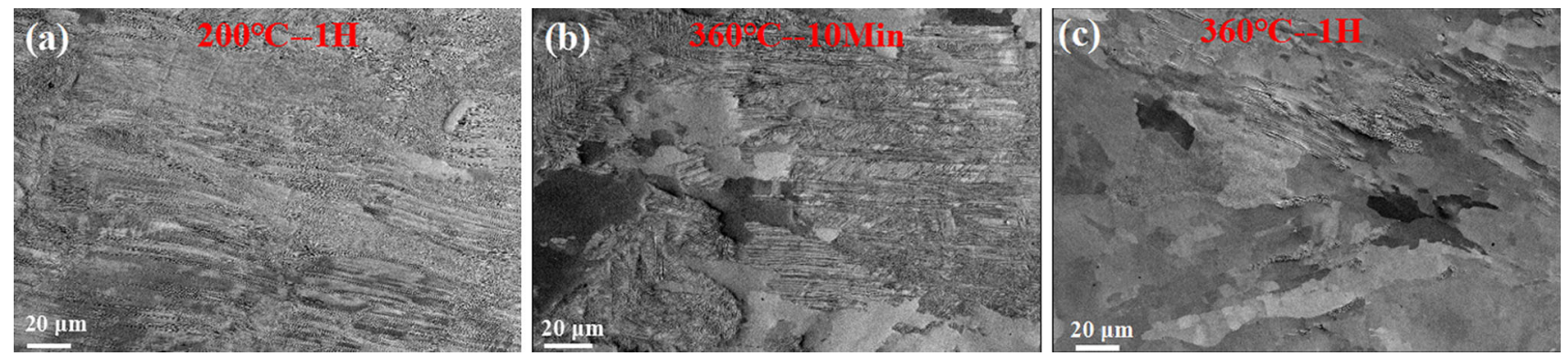

Fig. 6 Microstructural characteristics of ausformed Co sample with $40 \%$ reduction under different annealing treatment: a $200{ }^{\circ} \mathrm{C}-1 \mathrm{~h}$; b $360{ }^{\circ} \mathrm{C}-10 \mathrm{~min}$; c $360{ }^{\circ} \mathrm{C}-1 \mathrm{~h}$

EBSD was also carried out for the $40 \%$ ausformed Co after annealing treatment. The IPF maps of annealed $40 \%$ ausformed Co (Fig. $7 \mathrm{a}_{1}-\mathrm{c}_{1}$ ) show that the amounts of recrystallized grain gradually increase. In addition, the annealing texture is gradually close to basal texture, which is the recrystallized basal texture. The phase maps of Fig. $7 \mathrm{a}_{2}-\mathrm{c}_{2}$ indicate that $\gamma \rightarrow \varepsilon$ transformation occurs during the recrystallization process, revealing that the annealing treatment can induce $\gamma \rightarrow \varepsilon$ phase transformation. GB maps of Fig. $7 a_{3}-c_{3}$ show that the $\sum 3$ boundaries, SBs $\left(70.5^{\circ} /<11 \overline{2} 0>\right)$, and LABs in ausformed Co samples gradually disappear as the prolonging holding time and the increasing annealing temperature.

Figure 8 shows the schematic illustrations of microstructure evolution for the ausformed Co. Figure 8a shows the received Co samples with the fully recrystallized microstructure. Figure $8 \mathrm{~b}$ shows the hot-rolling microstructure in one prior austenite grain. The individual prior austenite grain is subdivided into the different regions (cell blocks), as a consequence of the compatibility deformation among the different regions in one individual grain [32]. In one cell block, the dislocations in Co with fcc structure at elevated temperature can be introduced along $\{111\}$ slip planes, as confirmed by the different flow directions in the cell block in Figs. 1 and 2. The movement and interaction of high density of dislocations during hot-rolling process can induce LABs, as confirmed in Figs. 3, 4, 5.

The hot-rolling $\mathrm{Co}$ is subsequently treated by water cooling, and then the ausformed Co can be obtained after $\gamma \rightarrow \varepsilon$ phase transformation. Figure 8c shows the microstructure of the ausformed $\mathrm{Co}$, which consists of the blocky and acicular laths, as indicated in Figs. 1, 2, 3, 4, 5.

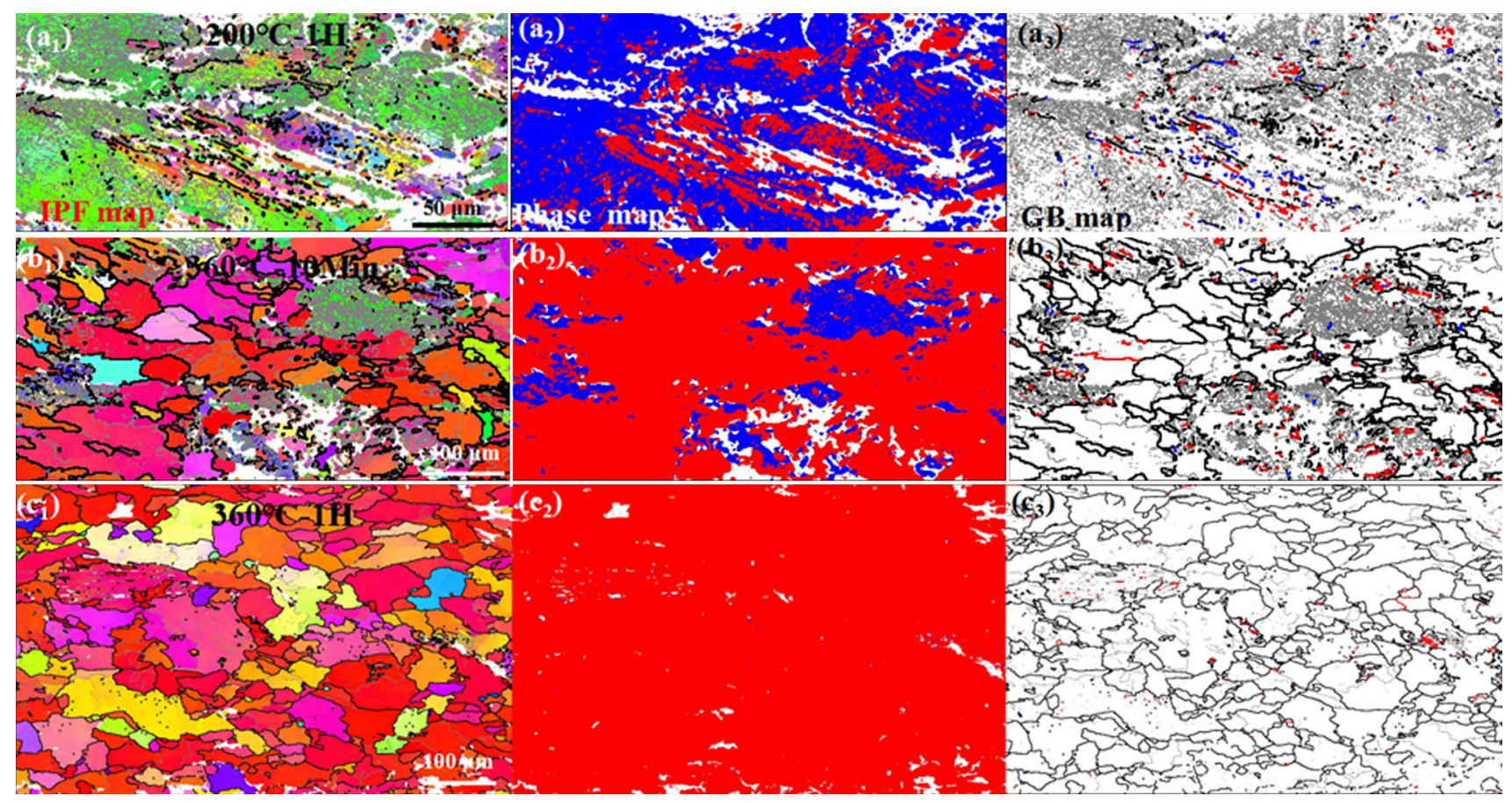

Fig. 7 EBSD images (IPF, phase and GB maps) showing ausformed Co samples after annealing treatment: a $200{ }^{\circ} \mathrm{C}-1 \mathrm{~h}$; b $360{ }^{\circ} \mathrm{C}-10 \mathrm{~min}$; c $360{ }^{\circ} \mathrm{C}-1 \mathrm{~h}$ 

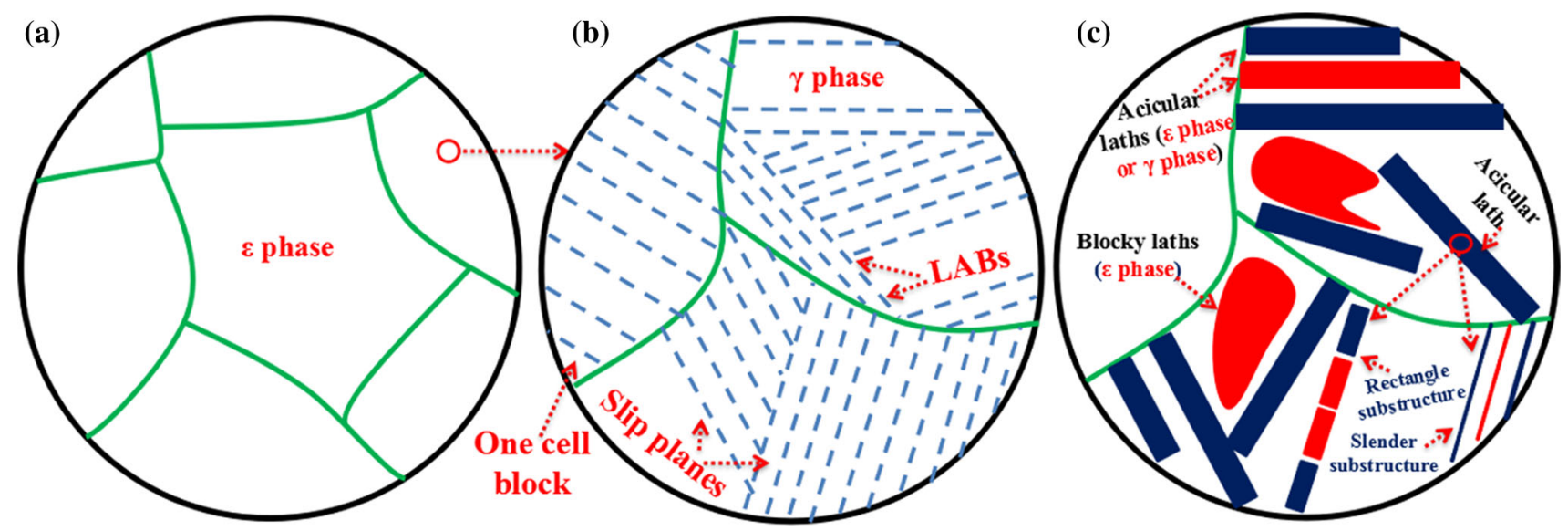

Fig. 8 Schematic illustrations of microstructural evolution for ausformed Co sample. a Recrystallated grains for received state, $\mathbf{b}$ deformation behaviours in cell blocks during hot-rolling process, c acicular and blocky laths in ausformed Co sample

The acicular laths, including slender and rectangle substructures, are corresponding to $\gamma$ or $\varepsilon$ phases, which indicates that $\gamma \rightarrow \varepsilon$ transformation in the acicular laths has not been completed, i.e., stabilization of residual austenite $\gamma$ phase. The underlying reason can be explained by the followings: The slender and rectangle substructures with ultra-fined size lead to large proportion areas for grain boundaries. Grain boundary atoms are relatively stable during $\gamma \rightarrow \varepsilon$ transformation since they are partly free from restriction by neighboring atoms and tend not to take part in the coordinated atom movements of such transformations [26]. Thus, grain boundaries can stabilize the parent phase and then hinder $\gamma \rightarrow \varepsilon$ transformation, leading to the residual $\gamma$ phase in the acicular laths. In addition, one reason can be ascribed to the formation of blocky laths. The inhomogeneous deformation during hotrolling can lead to the undeformation regions. Subsequently, the undeformation regions ( $\gamma$ phase) can transform into $\varepsilon$ phase during the subsequent cooling process. Thus, the blocky laths belonging to $\varepsilon$ phase (Figs. 3, 5) can be the result of the $\gamma \rightarrow \varepsilon$ transformation of the inhomogeneous deformation microstructure.

Two metallurgical processes are involved, including recrystallization and annealing-induced $\gamma \rightarrow \varepsilon$ transformation. The recrystallization process can be described as follows. The free energy of a crystalline Co can be raised by the abundant lattice defects existing in LABs, $\sum 3$ boundaries and SBs. Thus, the ausformed Co microstructure is thermodynamical unstable, generating that the recrystallization process can be accelerated when the ausformed Co is annealed. Thus, the driven force of recrystallization process arises from the elimination of the defects introduced by ausforming. It is worth mentioning that the recrystallization grains in Co grow slowly due to the sluggish boundary migration effect [25]. For example, the heat treatment $\left(360{ }^{\circ} \mathrm{C}\right.$ for $\left.48 \mathrm{~h}\right)$ was carried out to obtain fully recrystallized Co $[30,31]$. More specially, the almost recrystallization microstructure can be obtain in ausformed Co under $360{ }^{\circ} \mathrm{C}$ for $1 \mathrm{~h}$. Thus, the ausforming can accelerate the recrystallization process of Co due to the fact that the abundant lattice defects formed after the ausforming process, which can provide the driven force for recrystallization process.

The effects of holding time and annealing temperature for annealing-induced phase transformation in the ausformed Co have been investigated (Figs. 6, 7). The residual $\gamma$ phase in the ausformed Co almost disappears in a matrix of $\varepsilon$ phase at a certain elevated temperature of $360{ }^{\circ} \mathrm{C}$ for $1 \mathrm{~h}$. More interestingly, the annealing temperature has remarkable influences than the holding time, as confirmed in the $200{ }^{\circ} \mathrm{C}-1$-h specimen (Figs. 6a, 7a) and $360^{\circ} \mathrm{C}-10$-min specimen (Figs. 6b, 7b). The annealing-induced phase transformation can be ascribed as follows. The transformation kinetics for $\gamma \rightarrow \varepsilon$ transformation mechanism can be used to calculate the Gibbs free energy $\left(\Delta G^{\gamma \rightarrow \varepsilon}\right)$ change between hcp and fcc structures in Co [33]. It is reported that the differences in Gibbs free energy and its temperature coefficient between the two phases ( $\varepsilon$ and $\gamma$ ) in Co are small [26], so the driven force for $\gamma \rightarrow \varepsilon$ transformation in Co is small. In addition, the transformation driven force can be assisted by stress and strain, which can be produced from the large boundary areas in the ausformed microstructure. Thus, $\gamma \rightarrow \varepsilon$ transformation takes place and then reaches its equilibrium state during the annealing treatment. Furthermore, the extended holding time and the increasing annealing temperature can lead to higher degree of $\gamma \rightarrow \varepsilon$ transformation (Figs. 6, 7). 


\section{Conclusions}

(1) The morphological characteristics of the ausformed Co samples consist of the coarsen blocky laths $(\varepsilon$ phase) with irregular shapes and the ultra-fined acicular laths ( $\gamma$ and $\varepsilon$ phase) with slender and rectangular morphological characteristics. $\sum 3$ boundaries in $\gamma$ phase and SBs with $70.5^{\circ} /<11 \overline{2} 0>$ in $\varepsilon$ phase are observed. As compared to the slight reduction sample, the much denser laths are observed in the heavily ausformed sample.

(2) Two metallurgical behaviors occur in the ausformed Co samples after annealing treatment, including the recrystallization and annealing-induced $\gamma \rightarrow \varepsilon$ transformation. The extended holding time and the increasing annealing temperature can lead to the higher degree of recrystallization and $\gamma \rightarrow \varepsilon$ transformation. The driving force for recrystallization and phase transformation process can be provided by the large grain boundary areas with an abundance of lattice defects, which are formed during the ausforming process.

Acknowledgements This work was supported by the National Natural Science Foundation of China (Nos. 51501026 and 51401039), the Natural Science Foundation of Chongqing (CSTC2014jcyjA50017), the Scientific and Technological Research Program of Chongqing Municipal Education Commission (No. KJ1500923), and the Australian Research Council.

\section{References}

[1] R. Valiev, Y. Estrin, Z. Horita, T. Langdon, M. Zehetbauer, Y. Zhu, Mater. Res. Lett. 4, 1 (2016)

[2] T.G. Langdon, Acta Mater. 61, 7035 (2013)

[3] Y. Estrin, A. Vinogradov, Int. J. Fatigue 32, 898 (2010)

[4] F. Djavanroodi, A. Zolfaghari, M. Ebrahimi, K. Nikbin, Acta Metall. Sin. (Engl. Lett.) 27, 95 (2014)

[5] R.G. Guan, D. Tie, Acta Metall. Sin. (Engl. Lett.) 30, 1 (2017)

[6] Y. Estrin, A. Vinogradov, Acta Mater. 61, 782 (2013)

[7] R. Valiev, I. Alexandrov, N. Enikeev, M.Y. Murashkin, I. Semenova, Rev. Adv. Mater. Sci. 25, 1 (2010)
[8] A. Azushima, R. Kopp, A. Korhonen, D.Y. Yang, F. Micari, G.D. Lahoti, P. Groche, J. Yanagimoto, N. Tsuji, A. Rosochowski, A. Yanagida, Manuf. Technol. 57, 716 (2008)

[9] T. Sakai, A. Belyakov, R. Kaibyshev, H. Miura, J.J. Jonas, Prog. Mater. Sci. 60, 130 (2014)

[10] S. Tirekar, H.R. Jafarian, A.R. Eivani, Mater. Sci. Eng. A 684, 120 (2017)

[11] M.T. Pérez-Prado, O. Ruano, Scr. Mater. 51, 1093 (2004)

[12] H. Chang, M. Zheng, G.B. Heinz, W. Gan, Acta Metall. Sin. (in Chinese) 53, 220 (2017)

[13] C. Haase, O. Kremer, W. Hu, T. Ingendahl, R. Lapovok, D.A. Molodov, Acta Mater. 107, 239 (2016)

[14] C.F. Gu, L.S. Tóth, D.P. Field, J.J. Fundenberger, Y.D. Zhang, Acta Mater. 61, 3027 (2013)

[15] F.Y. Dong, P. Zhang, J.C. Pang, Q.Q. Duan, Y.B. Ren, K. Yang, Z.F. Zhang, Acta Metall. Sin. (Engl. Lett.) 29, 140 (2016)

[16] A. Simar, Y. Bréchet, B. De Meester, A. Denquin, C. Gallais, T. Pardoen, Prog. Mater. Sci. 57, 95 (2012)

[17] R. Nandan, T. DebRoy, H. Bhadeshia, Prog. Mater. Sci. 53, 980 (2008)

[18] Z.J. Yan, X.S. Liu, H.Y. Fang, Acta Metall. Sin. (Engl. Lett.) 29, 1161 (2016)

[19] A.P. Zhilyaev, T.G. Langdon, Prog. Mater. Sci. 53, 893 (2008)

[20] A. Zafari, X. Wei, W. Xu, K. Xia, Acta Mater. 97, 146 (2015)

[21] R. Pippan, F. Wetscher, M. Hafok, A. Vorhauer, I. Sabirov, Adv. Eng. Mater. 8, 1046 (2006)

[22] L. Zhao, N. Park, Y. Tian, S. Chen, A. Shibata, N. Tsuji, Mater. Res. Lett. 5, 61 (2016)

[23] P. Gong, E. Palmiere, W. Rainforth, Acta Mater. 119, 43 (2016)

[24] N. Tsuji, T. Maki, Scr. Mater. 60, 1044 (2009)

[25] W. Betteridge, Prog. Mater. Sci. 24, 51 (1980)

[26] Z. Nishiyama (ed.), Martensitic Transformation (Elsevier, Amsterdam, 2012)

[27] X. Wu, N. Tao, Y. Hong, J. Lu, K. Lu, Scr. Mater. 52, 547 (2005)

[28] I. Nikulin, T. Sawaguchi, K. Ogawa, K. Tsuzaki, Acta Mater. 105, 207 (2016)

[29] K. Yamanaka, M. Mori, Y. Koizumi, A. Chiba, J. Mech. Behav. Biomed. 32, 52 (2014)

[30] J. Tu, S. Zhang, T. Zhou, H. Tang, Z. Zhou, Mater. Charact. 119, 34 (2016)

[31] J. Tu, S. Zhang, Z. Zhou, H. Tang, Mater. Charact. 112, 219 (2016)

[32] N. Hansen, C.Y. Barlow, Plastic Deformation of Metals and Alloys, 2nd edn. (Elsevier, Oxford, 2014), pp. 1681-1764

[33] A. Rollett, F. Humphreys, G.S. Rohrer, M. Hatherly, Recrystallization and Related Annealing Phenomena (Elsevier, Amsterdam, 2004), p. 302 